CASE REPORT

\title{
Perforating Pancreatic Injury: New Approaches and Unexpected Complications
}

\author{
Leonardo KS Koyama ${ }^{1}$, Alissom V Cincoto ${ }^{2}$, Adriano RM Pflug ${ }^{3}$, Francisco de Salles Collet e Silva ${ }^{4}$, Edivaldo M Utiyama ${ }^{5}$
}

\begin{abstract}
Perforating pancreatic injury (PPI) is an uncommon event in trauma centers. In rare cases, it can complicate with pancreatic fluid collections (PFC). Although it is well known in cases of acute pancreatitis, there are few described cases in trauma patients. Another feared complication is the disconnection of the major pancreatic duct (MPD), which most authors recommend to be treated immediately. We hereby report a successful case of PPI that was initially approached by videolaparoscopy, coursed with an infected PFC formation and a MPD disconnection. This case analysis suggests that videolaparoscopy may be feasible in patients with PPI and that minimally invasive approaches in the acute phase might postpone more aggressive procedures to an elective and well-planned approach.
\end{abstract}

Keywords: Firearm, Laparoscopy, Pancreas, Trauma.

\section{RESUMO}

O ferimento pancreático perfurante é um evento raro em centros de trauma. Em alguns casos, pode complicar com coleções de líquidos pancreáticos Essas coleções são frequentes nos casos de pancreatite aguda, já nos casos de ferimentos pancreáticos há poucos casos descritos. Outra complicação temida é a desconexão do ducto pancreático principal, que a maioria dos autores recomenda que sejam tratados imediatamente. Neste artigo, relatamos um caso bem-sucedido de paciente com ferimento pancreático que foi abordado inicialmente por videolaparoscopia, cursado com uma formação de coleção peripancreatica infectada e uma lesão do ducto pancreático principal. Essa análise de caso sugere que a videolaparoscopia pode ser viável em pacientes com ferimentos pancreáticos penetrantes e que abordagens minimamente invasivas na fase aguda podem evitar procedimentos cirúrgicos mais agressivos para uma abordagem eletiva e bem planejada.

Palabras clave: Arma de fogo, Laparoscopia, Pâncreas, Trauma

Panamerican Journal of Trauma, Critical Care \& Emergency Surgery (2019): 10.5005/jp-journals-10030-1255

\section{BACKGROUND}

Perforating pancreatic injuries (PPI) are uncommon events in trauma, occurring in less than $2 \%$ of all trauma cases. ${ }^{1}$ They result in high morbimortality due to lesion of important veins and close organs or to the development of pancreatitis and abdominal infections. There is no consensus in its treatment as most authors would recommend an open surgery approach with distal pancreatectomy, while others suggest that an endoscopic recanalization of the duct by stent should take place.

Uncommonly these cases may complicate into the formation of a PFC, related to acute pancreatitis. Although unusual, cases of acute PFC can be managed endoscopically, by using a plastic drain, risking a possible bleeding or prosthesis migration. ${ }^{2}$

MPD discontinuity may be diagnosed by a MPD's cutoff in the endoscopic reverse pancreatography (ERP) and a vascularized distal pancreas in the computed tomography (CT) or with MPD discontinuity in the magnetic resonance cholangiopancreatography (MRCP). The discontinuity can lead to persistent PFC, fistula formation and recurrent pancreatitis. ${ }^{3}$ Depending on the degree of the lesion, it may be surgically treated, with resection of the distal pancreas to the point of discontinuity, or endoscopically, by stent placement. Most authors agree that the timing for surgical intervention has a high impact in the results, as an acute phase pancreatectomy can lead to high a morbidity of $40 \%$ and a mortality of $5.8 \%{ }^{4}$

Some authors suggest that the initial approach for all perforating trauma, especially with pancreatic involvement,
${ }^{1}$ Department of General Surgery, Hospital das Clínicas da Universidade de São Paulo, São Paulo, Brazil

2,5Department of Surgery, University of São Paulo, School of Medicine, São Paulo, Brazil

${ }^{3,4}$ Department of General and Trauma Surgery, Hospital das Clínicas da Universidade de São Paulo, São Paulo, Brazil

Corresponding Author: Francisco de Salles Collet e Silva, Department of General and Trauma Surgery, Hospital das Clínicas da Universidade de São Paulo, São Paulo, Brazil, Phone: +1 55555 5050, e-mail: fcolletesilva@gmail.com

How to cite this article: Koyama LKS, Cincoto AV, Plug ARM, et al. Perforating Pancreatic Injury: New Approaches and Unexpected Complications. Panam J Trauma Crit Care Emerg Surg 2019;8(3): 187-190.

Source of support: Surgical Emergency Service of Hospital das Clinicas, University of São Paulo, School of Medicine, São Paulo, Brazil

Conflict of interest: None

should include a laparotomy, once the imaging of the abdomen could be a false-negative. ${ }^{3}$ However, some recent studies suggest that, in hemodynamically stable perforating trauma patients, a laparoscopic approach could be used as first approach, preventing unnecessary laparotomies and reducing the hospital stays. ${ }^{5}$ Nevertheless, there is no study comparing laparoscopic and open surgical approaches when PPI is present.

() The Author(s). 2019 Open Access This article is distributed under the terms of the Creative Commons Attribution 4.0 International License (https://creativecommons. org/licenses/by-nc/4.0/), which permits unrestricted use, distribution, and non-commercial reproduction in any medium, provided you give appropriate credit to the original author(s) and the source, provide a link to the Creative Commons license, and indicate if changes were made. The Creative Commons Public Domain Dedication waiver (http://creativecommons.org/publicdomain/zero/1.0/) applies to the data made available in this article, unless otherwise stated. 


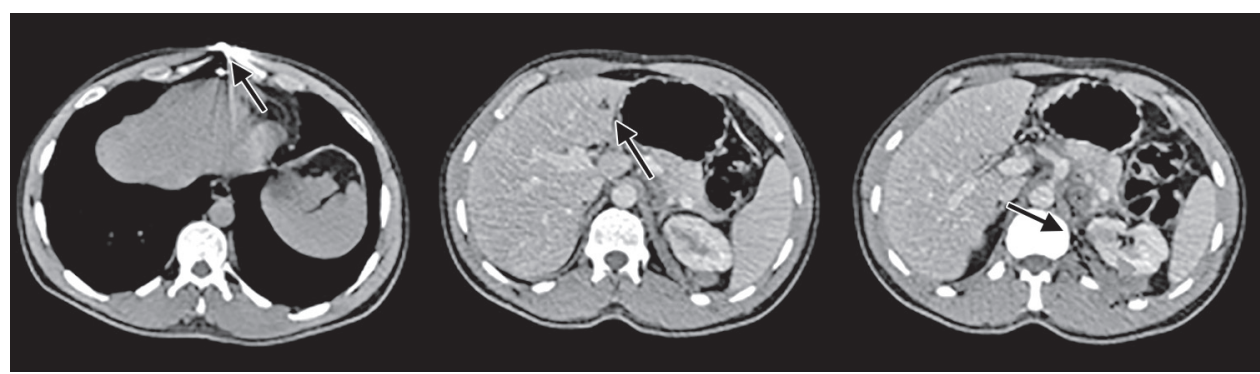

Fig. 1: Initial CT with the bullet in epigastric, the segment 2 and left kidney lacerations and the small pneumoperitoneum
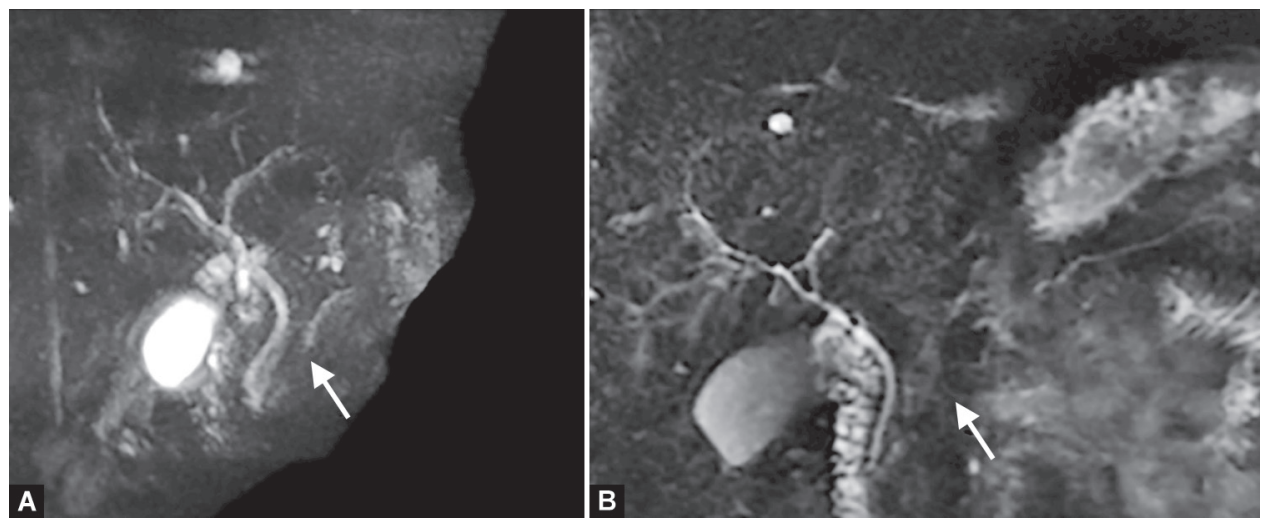

Figs $2 A$ and $B:$ MRCP with MPD disconnection

\section{Case Description}

A 33-year-old previously health patient was brought to our service with an hour history of gunshot. He was conscious, mildly tachycardic, with adequate blood pressure and peripheral perfusion. One bullet entry hole was seen in the second lumbar (L2) level, $4 \mathrm{~cm}$ left to the mid-dorsal line with no active bleeding and no exit hole. Additionally, there was no sign of peritonitis.

As he remained hemodynamically stable, a thoracic, abdominal and pelvic CT was performed (Fig. 1). This CT showed that the bullet entered in L2 level by the left psoas muscle, went through the retroperitoneum to the abdominal cavity, lacerating the left kidney, the proximal third of the pancreas' tail and the liver segment 2. A laparoscopic first-approach was chosen. Intraoperatively, a gastric lesion was sutured, without the need to convert to a laparotomy.

In the immediate postoperative (PO) the patient experienced important abdominal pain and elevation of serum amylase, lipase, $\mathrm{C}$-reactive protein and leukocytosis. Hence, he was sent to an intensive care unit (ICU), where progressive improvement of the pain and laboratory parameters took place. He was discharged from the ICU in the fourth PO. In the ward, he was submitted to a MRCP that showed a disconnection between the caudal MPD and the hepatopancreatic duct (Fig. 2). The patient showed new clinical deterioration with fever, leukocytosis and abdominal pain in the 15th PO, leading to a new $\mathrm{CT}$, which revealed a PFC formation, with regional lymphadenopathy (Fig. 3). Also, a broader spectrum antibiotic (meropenem) was introduced, following the unit guidelines for hospital-acquired infection. An ERP was then performed, with the passage of a $7 \mathrm{Fr} \times 12 \mathrm{~cm}$ prosthesis, cannulating the MPD from the pancreatic tail to the duodenal papilla, that drained a purulent liquid (Fig. 4). The patient evolved with progressive clinical and laboratorial improvement and was discharged from the hospital in the 24th PO.

The patient had no symptom since then. In the 15-days return, he presented with a new CT showing a prosthesis dislocation to the jejunum and after 6 months the prosthesis was not visualized. As the MPD disconnection was still present, a new ERP was performed, which showed a MPD stenosis that prevented the passage of the guidewire (Fig. 5). Therefore, an elective caudal pancreatectomy is scheduled.

\section{Discussion}

We reported a case of PPI, with rare complications but successful treatments that allowed this patient to have a hospital discharge and an elective pancreatic approach.

Initially, the arrival of an open trauma prompted to a laparotomy, as some authors suggest that a CT scan could be misleading. However, the patient's stability, with no important hemorrhagic lesion, the new literature findings with the improvement of the $\mathrm{CT}$ technology, the development of the laparoscopic techniques and the team's surgical expertise lead us to think that an initial laparoscopic approach could prevent a laparotomy. Besides the initial stability, surgery was crucial, since the CT suggested gastric perforation.

The care of this patient in the PO also leads to discussion, since the pancreatic lesion was not surgically treated. As the MPD visualization in CT is only possible in pancreatic transections, these 


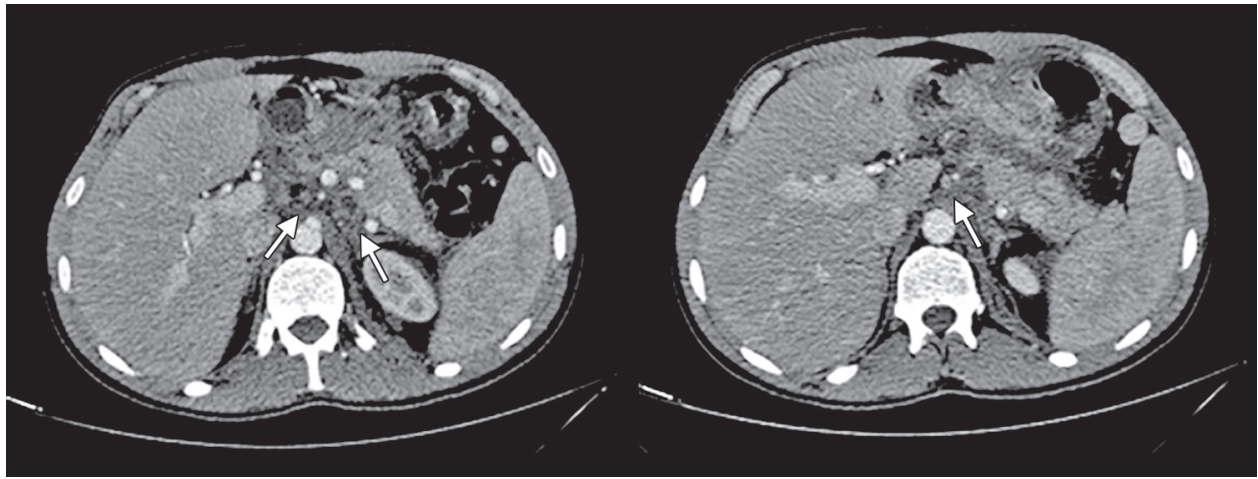

Fig 3: 15th PO CT with PFC, hyperdense fat and lymphadenopathy

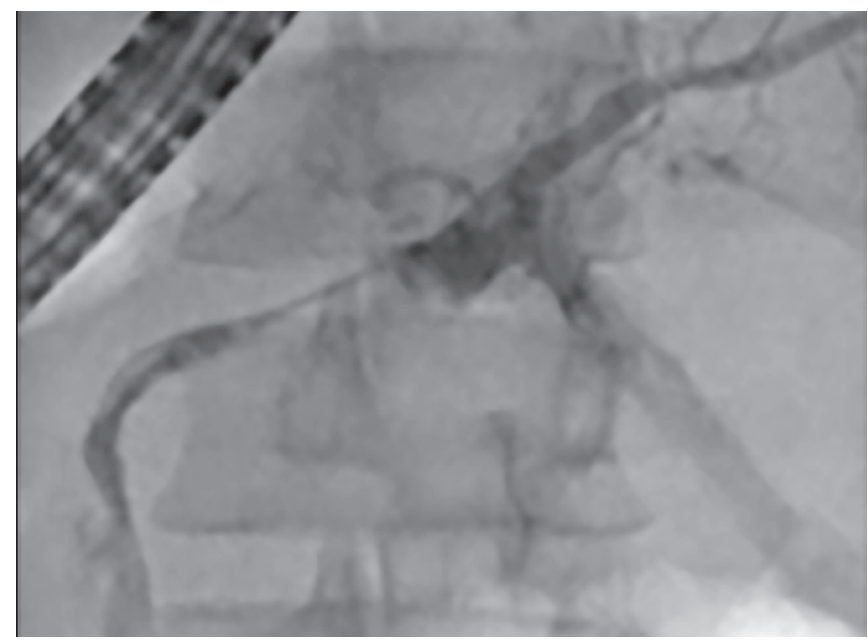

Fig. 4: ERP in the 16th PO with allocated prosthesis and MPD visualization

patients should have a MRCP or an ERP in the hospital stay. We opted to begin with the MRCP, considering it has few contraindications, it is a not invasive method and it is available in our service. The imaging showed us a rare complication of PPI: MPD discontinuity and a disconnection of approximately $1 \mathrm{~cm}$. Therefore, our initial decision was a nonsurgical approach, once most ducts heal if the disconnection is less than $2 \mathrm{~cm}$ distance.

Nevertheless, an abdominal sepsis occurred in the 15th PO from which a new CT scan showed an infected PFC. As there was a disconnection in the MPD and because of the urge to drain the MPD, we opted to insert a prosthesis that successfully drained the collection and could restore the MPD flow. This approach is less invasive, may avoid or delay surgery and, if it is still necessary to operate, it facilitates a intraoperative pancreatography, ${ }^{6}$ although the prosthesis may dislocate into the gastrointestinal tract, ${ }^{2}$ which happened to our patient. This approach may have taken a part in the damage of the MPD.

Initially, because the disconnection was $1 \mathrm{~cm}$ far and the patient was stable, with no abdominal pain, it was decided to watch and wait. However, after 6 months, as the disconnection image did not regenerate, a new ERP was performed to investigate the MPD and, if possible, to drain the occluded duct by a stent. This approach

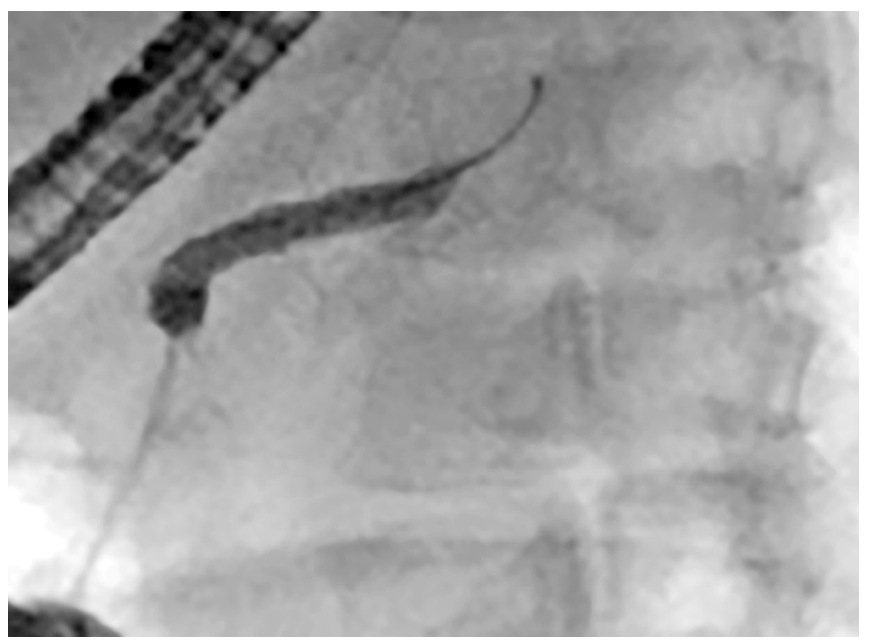

Fig. 5: ERP 6 months after the trauma: MPD's abrupt cutoff

was not possible, however, because the guidewire did not pass the occlusion which lead to surgery indication.

\section{Conclusion}

We presented a case of rare, yet possible complications of both the trauma and the medical interventions. This case showed the possibility of use of many options already validated in acute pancreatitis in a PPI patient, with satisfactory results. Although our patient still needed a pancreatectomy, the surgery could be postponed for 2 years, which gave him the chance to have an elective approach and to avoid an urgent procedure while in the trauma inflammatory response. Therefore, we believe that, although there are no studies supporting the use of new technological advances in PPI, they can be successfully used in selected patients, with possibly better results than the conventional approach.

\section{References}

1. Kollar D, Molnar FT, Zsoldos $\mathrm{P}$, et al. Diagnosis and management of blunt pancreatic trauma. Orv Hetil 2018;159(2):43-52. DOI: 10.1556/650.2018.30938. 
2. Chinnery GE, Krige JE, Kotze UK, et al. Surgical management and outcome of civilian gunshot injuries to the pancreas. Br J Surg 2012;99(Suppl 1):140-148. DOI: 10.1002/bjs.7761.

3. Nabi Z, Lakhtakia S, Basha J, et al. Endoscopic drainage of pancreatic fluid collections: long-term outcomes in children. Dig Endosc 2017;29(7):790-797. DOI: 10.1111/den.12884.

4. Crisanto-Campos BA, Arce-Lievano E, Cardenas-Lailson LE, et al. Laparoscopic management of pancreatic pseudocysts: experience at a general hospital in Mexico City. Rev Gastroenterol Mex 2015;80(3):198-204. DOI: 10.1016/j.rgmx.2015.05.003.

5. Kawahara NT, Alster C, Fujimura I, et al. Standard examination system for laparoscopy in penetrating abdominal trauma. J Trauma 2009;67(3):589-595. DOI: 10.1097/TA.0b013e3181a60593.

6. Kozarek RA, Ball TJ, Patterson DJ, et al. Endoscopic transpapillary therapy for disrupted pancreatic duct and peripancreatic fluid collections. Gastroenterology 1991;100(5 Pt 1):1362-1370. 